\title{
Crítica ou críticos: um dilema do teatro
}

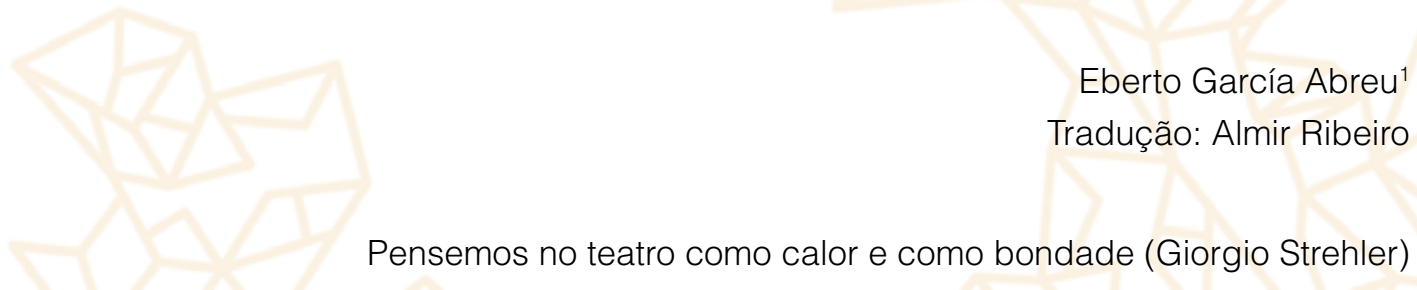

Quando perguntaram pela primeira vez o que era para mim o teatro, pensei que minhas palavras podiam abarcar os confins cada vez mais distantes desta expressão artística. Não me recordo com precisão minha resposta na ocasião, mas agora sim, tenho muito clara a consciência de que, com o tempo, responder semelhante pergunta se tornou um enigma perigoso. Ao adentrarmos nas complexidades e nas seduções da linguagem teatral, mais inefável ele se revela e mais difícil de se capturar em poucas palavras ele se torna. O mesmo me acontece, de forma natural, com a definição precisa do que é ou deve ser a crítica teatral.

Talvez seja mais viável nos desvencilharmos do que suspeitamos ou estamos convencidos do que não deve ser a crítica, não apenas no âmbito teatral, mas em qualquer universo artístico. Mas, por esse caminho podemos cair em um campo ainda mais improdutivo: padronizar regras, prescrever normas, estabelecer cânones. Para missões semelhantes me declaro totalmente incompetente. Por isso prefiro compartilhar as visões pessoais, mais ou menos certas, demonstradas durante quase duas décadas no exercício do critério, como certezas derivadas de um longo e permanente caminho de aprendizagem e prática do teatro a partir de seu corpo profundo e não a partir do limite que a condição de um espectador atento, avisado, especializado ou não, faz supor. Ainda que todas estas condições, logicamente, façam parte dessa segunda identidade, característica dos indivíduos dedicados, de uma ou outra forma, a oferecer suas opiniões sobre uma peça e desta maneira intervir na prática teatral.

Ao desenvolver a crítica no teatro, o que fazemos nada mais é que simplesmente ler através dos espetáculos, dos espectadores, dos textos dramáticos, da história do

\footnotetext{
${ }^{1}$ Eberto Garcia Abreu é professor titular de História e Teoria do Teatro no Instituto Superior de Arte de Cuba.
} 
teatro, das poéticas e dos livros, e até mesmo de muitas outras fontes, do imaginário subjacente a todo o momento e nas dimensões da teatralidade que a cada um lhe são contemporâneas e, a partir dessa perspectiva, interpretar, reinterpretar e inventar várias noções do teatro no futuro. A crítica acompanha o exercício cotidiano da criação teatral. Deixa sinais de seus passos em uma ou outra direção, mas estes sinais não devem ser vistos como referências inequívocas ou infalíveis. São registros que foram e continuarão sendo resultado dos olhares pessoais daqueles que a partir de diferentes posições, leram, concluíram, instrumentalizaram, descobriram os possíveis alcances das imagens teatrais, não importando seu suporte nem a forma concreta com que são apresentadas ao espectador ou ao leitor.

Alcançada esta primeira etapa de definições acerca da crítica, quero citar meu professor Rine Leal em seu livro indispensável Em Primera persona:

\begin{abstract}
Entre as muitas e variadas definições do homo criticus existe uma que sempre recebeu minha preferência: o crítico é um espectador especializado. Acredito entrever nestas palavras a chave fundamental da razão crítica. Nada de definições doutorais ou proveniente de algum tipo especial de inteligência, mas simplesmente uma condição profissional, uma presença assídua aos espetáculos e, claro, uma paciência jacobina. O crítico, portanto, não nasce espontaneamente, mas é formado com o fórceps da especialização. Como alguém pode se tornar um crítico de teatro? Certamente, e a história tanto cubana quanto universal comprovam que alguém se torna crítico da mesma maneira como qualquer um pode se tornar ator, se assim firmemente decidir... e tiver condições.

O que, então, distingue um espectador comum de um espectador crítico? $\mathrm{Na}$ falta da ingenuidade que o seu trabalho supõe, neste segundo olhar (The mind's eye de que fala Hamlet) que nos faz ver além das aparências da cena, e ao conceituar o teatro como uma situação da cultura e não um entretenimento ou negócio, ainda que possua ambas as coisas. O resto, bem, o resto é conhecimento do teatro, habilidade literária, sensibilidade, inteligência e leitores² (LEAL, 1967, p. 11).
\end{abstract}

Fazer crítica é um ato solitário de ler e assistir teatro e uma forma de participar do discurso construído em uma cena, em um retábulo, no meio de uma praça ou em qualquer outro lugar onde atores e espectadores façam visível o encanto das fabulações que ambos constroem, como representações de outros universos criativos ocultos e pulsantes. Nesse sentido, não penso que a crítica se expresse apenas através das palavras reunidas após o espetáculo, ou em raras ocasiões, antes da estreia, o confronto inevitável com o público. Pensar o teatro na totalidade de suas múltiplas e contrastantes relações é também criticar. Pois a verificação, a avaliação, o confronto de valores, a atestação de perícias técnicas ou desvarios inoportunos que afloram em um

\footnotetext{
${ }^{2}$ O grifo é meu, para chamar a atenção para a importante e necessária presença de interlocutores que ampliem, gerem e fundamentem o exercício do diálogo crítico a partir da diversidade de opiniões a respeitar.
} 
ou outro espetáculo e que logo, no dia seguinte, aparecem nas páginas dos jornais, é um feito tão evanescente e efêmero como a própria representação teatral. Estes são sinais de que depois falarão não só do trabalho dos artistas, em última análise sempre mais duradouro do que os testemunhos de seus avaliadores, mas também da visão subjetiva com que essas propostas teatrais foram acolhidas. Não se pode esquecer, portanto, que toda a nossa capacidade para devolver aos criadores e espectadores os registros de suas imagens, são cozinhados sob as mesmas condições históricas e contextuais que definem, sugerem ou indicam uma sensibilidade da época, a partir do qual participamos individual e socialmente, no exercício coletivo do teatro. Talvez por isso, o professor Eric Bentley dizia algo como cada teatro tem a crítica que merece.

Embora a questão não seja de simples merecimentos, muito de correto se encontra sob essas sábias palavras. Não podemos separar a crítica da criação, acima de suas expressões genéricas ou estilísticas, que são e devem ser muito diversas para justamente garantir a possibilidade do diálogo humano que o teatro demanda. Um diálogo que caminha, ou pelo menos deve possuir a capacidade de caminhar, do "aqui e agora" para o "passado" ou para o "futuro", inerente a toda concretização cênica, resultantes da acumulação, da sedimentação, e das aproximações que as imagens teatrais fornecem ao caminho vasto das dessemelhanças poéticas do teatro. Poéticas que não são abstrações ou elucubrações momentâneas dos artistas. Pelo contrário, cresceram a partir dos aportes de cada obra pensada, construída ou projetada para a cena ou a partir dela, sobre a qual o crítico realiza como espectador uma ação especializada, portadora de uma fruição carregada de maiores exigências e rigores. Ao mesmo tempo, mais que um ofício, é o exercício de uma fé, um ato de uma condição profissional. Nestas circunstâncias, o crítico alça o seu espaço natural, sobretudo porque também ele se arrisca neste processo de construção poética, enquanto elabora com suas opiniões, comentários, sugestões, sinalizações, interpretações, leituras em voz alta ou em branco e preto. Ele cria o espaço de suas próprias fabulações teatrais, assumindo assim não o papel passivo de um depositário de imagens que outros lhe sobrepõem, mas sim a atitude criativa, dinâmica e vital característica de todo e qualquer ato de invenção poética. Porque a crítica de teatro, assim como o teatro, também é, ou deveria ser, um ato de invenção poética. Assim acrescenta J. Middleton Murry, citado pelo professor Rine Leal:

O crítico, a menos que se trate dessa coisa estranha chamada crítico técnico, deve ser, até certo ponto, um artista criativo em sua crítica. A primeira parte 
de seu trabalho é transmitir o efeito, a impressão geral, intelectual e emotiva que the deixou o espetáculo que está criticando; sem este fundamento, sua opinião será estéril e inconsistente. Neste aspecto, sua tarefa é rigorosamente análoga à tarefa criativa do escritor (MURRY in LEAL, 1963, p.10).

Da mesma forma, eu comungo com as ideias de Strehler, um homem indispensável ao teatro:

\begin{abstract}
De um modo geral, todos os métodos são válidos. E mesmo os mais distintos personagens da crítica. Todos são viáveis e a sua maneira corretos com a condição que sejam honestos, ainda que cada um prefira um tipo de crítica mais que o outro. Eu, por exemplo, estimo pouco a crítica distraída, em parte humorística, que deprecia o evento teatral, a que brinca com ele. Prefiro a crítica poética, um tipo de crítica de emoção controlada que devolve um tremor ao evento teatral. Mas eu penso que um tipo de crítica não deveria poder existir: a crítica do desamor, a crítica da falta de responsabilidade (STREHLER, 1987)
\end{abstract}

Crítica poética ou poética crítica? Não são dualidades categóricas ou dicotomias. Não são alternativas. São fronteiras nas quais se encontram as encruzilhadas de nossos caminhos no teatro. Assim como deve acontecer com artistas e espectadores que não conseguem romper com o misterioso enfeitiçamento da teatralidade, para sorte de todos os que diligentemente insistimos em seguir fazendo presente esta arte milenar e distante. Por isso, precisamente, que não haja uma CRÍTICA TEATRAL, mas sim críticas teatrais e que existam críticos e críticos, unidos por uma condição equivalente; mas não aprisionados sob um manto igualitário que uniformiza os olhares e as opiniões, como tampouco ocorre com a linguagem teatral.

Nestes tempos que correm, assim como em tempos antigos, acredito que, para os críticos, quero dizer, para os profissionais especializados e permanentes do exercício do critério, transcendente à valoração ocasional ou a indiferença prepotente frente a toda e qualquer proposta, não nos resta muita margem para exercer plenamente a nossa profissão, a não ser cultivando nosso ofício o mais perto possível do ato de criação. Uno-me assim às inúmeras experiências legitimadoras da crítica participante, aquela que é gerada no interior do processo criativo, aquela que se escreve no palco e no corpo dos atores, incorporando as mesmas tensões geradas pelas expectativas ante a intervenção iminente do olhar dos espectadores. Isso não significa o estabelecimento de um falso compromisso ou a inibição do juízo crítico para operar sobre o discurso teatral desde a área criativa a qual o crítico deve corresponder em circunstâncias afins a esta perspectiva de trabalho. Nada mais longe dessa ideia de banalização de um ofício tão antigo, respeitado, injuriado, ignorado ou aclamado. Porque a verdade é que todas estas doenças permeiam a abordagem da gestão dos critérios, quando se 
a realiza sob imperativos circunstanciais, imersos nas correntes movediças da moda e das tendências. Quando não radicalmente inserida no tecido cultural do teatro e a partir do qual se valida como discurso estético e como discurso paralelo, simultâneo, interatuante com o eixo central e protagonista do teatro: a criação artística.

Na arte, como na literatura, uma das funções da crítica é precisamente
decifrar, a partir de uma determinada perspectiva, as chaves dos
significados que conduzam a uma proposta de leitura. Este processo implica
no estabelecimento de nexos profundos entre a obra e a época que a viu
surgir, a análise de seus valores e uma sensibilidade apurada para o seu
fruir. Porque a relação que a obra de arte estabelece com o seu público
não é unívoca. Quem vai até ela, carrega consigo sua própria experiência,
com a história das lutas e das necessidades de seu tempo, de sua era
(POGOLOTTI, 1983, p. 17)

A crítica, portanto, é um exercício cultural libertador. Isto quer dizer que supõe, implica e exige, além do ofício necessário para estabelecer a comunicação e a expressão das ideias através de diferentes meios, não apenas aqueles óbvios das publicações, um universo de amplas referências para estabelecer de maneira adequada as opiniões, as sugestões, e inclusive afirmar suas próprias visões criativas derivadas de seu imaginário subjetivo. Através do seu trabalho, o crítico pode conseguir iluminar as áreas obscuras de uma obra. Colocar luz onde outros veem apenas manchas ou sombras indecifráveis. Assim ele se aventura desde sua ação individual e solitária, repito, com todo seu conhecimento, paixão e urgência em reverenciar o teatro, em busca de caminhos alternativos para encurtar a distância entre criadores e espectadores. Para tais tarefas, o crítico, como o artista, deve ser livre para escolher para onde dirigir seus passos e estabelecer uma interação com as diferentes áreas operativas do teatro.

Enquanto público especializado, o crítico toma parte do processo de criação artística. (...) O espectador fecha o processo de criação que começa na solidão do dramaturgo, e o crítico, público público, é o seu representante ideal. Pela mesma razão que uma obra teatral não existe sem o seu público, tampouco poderá existir sem seu crítico ${ }^{3}$ (LEAL, 1967).

Desde os mais diversos púlpitos acadêmicos e educacionais, desde as imprescindíveis atividades editoriais, desde os complexos meandros da gestão e da produção teatral, em meio às respostas imediatas que a imprensa escrita ou audio-

\footnotetext{
${ }^{3}$ Reproduzo literalmente esta citação do prefácio de Rine Leal a seu livro En Primera Persona, citado anteriormente, pela precisão de sua conceituação em relação a um teatro que assume como prática habitual a encenação a partir da existência prévia do texto dramático, eixo "principal" que articula todo o processo de montagem e realização do espetáculo. A citação, de 1967, não contém pontos de vista, obviamente mais amplos e contemporâneos que o próprio Rine veio a compreender e ensinar a todos os que tiveram a sorte de aprender ao seu lado.
} 
visual demanda, ou no ofício do dramaturgo que anda a caça das imagens latentes nos textos e nos palcos, reunindo autores, personagens, histórias, temas, processos e métodos de criação, atores, diretores e espectadores; entre tão rica encruzilhada de opções e oportunidades, o crítico abre caminho para o seu trabalho, companheiro inseparável do teatro.

É verdade que as palavras ou ideias que descansam nas páginas de um livro ou uma revista são menos perecíveis, graças a elas podemos encontrar os ecos da história e colocar em primeiro plano os grandes problemas que alimentam as reflexões teóricas instauradas desde a criação, a circulação e a recepção do teatro em suas várias eras. Mas essa não é a única opção possível. Como estações, o crítico pode e deve percorrê-las, sem nunca renunciar ao caráter transitório e comunicativo de sua ação. Assim como os espetáculos e as representações, também a crítica deve se contaminar com a dimensão efêmera, ou seja, temporária, de qualquer obra de abordagem poética presente no mundo teatral do qual fazemos parte.

Talvez por estas razões, com o tempo, também me veio ao corpo uma maior tranquilidade para aceitar o fato indiscutível, pelo menos para mim, que o teatro existe para além das nossas geografias e tempos imediatos. Isso se mostra apenas nas oportunidades que o acaso nos propõe, mesmo em nossa própria cidade ou em nosso ambiente. Embora seja necessário manter vivo o interesse em acessar a todos os gestos que o teatro nos oferece, não podemos pretender abarcar a totalidade do teatro. Cada um de nós é definido em relação às obras que nos pertencem. Quando conhecemos o teatro dos colegas de profissão de outras regiões, imediatamente dirigimos o olhar em direção a nosso centro criativo, não porque acreditamos que a nossa aldeia seja o mundo, como muito oportunamente advertiu José Martí em seu ensaio Nuestra América, mas porque submetemos nossas próprias regras de valor e percepção a verdadeiros enfrentamentos e confrontos. Assim crescemos, mas não permutamos nossos pontos de vista.

Daí que o teatro latino-americano ou de qualquer outra região, também pode chegar a nos pertencer, promovendo o intercâmbio com outros homens e mulheres, e isso pode ser possível acima de qualquer história ou formulação. Isso é possível por um gesto de convocação peregrina, duradoura, revolucionária e pacífica do teatro em todas as latitudes espaciais e históricas. Nesta força se inspirou meus maiores projetos críticos ao longo de minha vida no teatro: a investigação para a cena e a 
partir dela, a prática apaixonada da docência, o trabalho de dramaturgista realizado sistematicamente com vários grupos de teatro e dança e em obras para a televisão, cinema e rádio, bem como a fundação e desenvolvimento do Taller Itinerante de La Crítica, um espaço plural de opiniões, que durante quase cinco anos permitiu a mim e a muitos críticos e artistas cubanos, partilhar nossas esperanças e nossos critérios in loco, ou seja, junto aos artistas, durante os ensaios ou imediatamente após uma estreia, durante a escrita das peças ou em pleno ato de indagação ou de gestação de um espetáculo ou uma temporada. Um intercâmbio arriscado e intangível, convertido em patrimônio vivencial protagonizado pelos artistas, destinatários principais de meu trabalho como crítico, enquanto eles, com as suas imagens me aproximam também destes homens e mulheres que nas salas com poltronas ou nas praças ou nas ruas me acompanham no difícil papel de espectador, tanto nos cenários habituais de minha ilha a qual o teatro rodeia, como água, por todos os lados, ou em cenários ocasionais aos quais tenho ido nos países de nossa América, na distante Ásia e na Europa vetusta e recorrente.

Espaços dessemelhantes que a memória guiada pelo acaso se ocupa de compor como se fosse um estranho labirinto povoado por Ícaros e Dédalos, Ágaves, Teseus, Dionisos, Luz Marinas, Hamlets, Tavitos, Ninas, Santa Camilas, Pasolinis, Galápagos, Zuccos, Carlos Perez Peña e suas vozes, Vicente Revuelta e Galileus, Brecht e Raquel Revuelta com a Mãe Coragem gritando com paixão, Flora Lauten e os Buendía, Rine Leal, onde quer que esteja, Peter Brook no porão da casa de Stanislavski, Bulgakov, Goncharov e Maria Elena Ortega e José Milián colocando-me de frente com o Realismo em um frio inverno moscovita antes da queda do muro de Berlim, o silêncio de Maeterlinck e os modelos atuacionais de Pavis e Gloria María Martínez com Strindberg e o Fausto, o Teatro Escambray, meu teatro, e Graziella Pogolotti com suas lições de humanismo e cultura permeadas pelo teatro, e Roberta Carrieri, Julia Varley, Eugenio Barba e os Odins, e Patricia Alves que me obriga a contar mesmo os minuto menos importantes e Santiago Garcia e Patricia Ariza com todo o Teatro La Candelaria fazendo En la Raya, El Paso, El Quijote..., e por lá o Ictus, do Chile, o antigo Rajatablas, Denise Stocklos, Darío Fo, El Galpón de Atahualpa, Don Atahualpa, com ele, e Yuyachkani, Miguel Rubio e Teresa Rali, o Teatro Galpão de Belo Horizonte e Sara Baras fazendo Mariana Pineda e Boris Villar e Maribel Barrios com seu pequeno Antoine, me dizendo Adeus, a Deus, Deus... e meus colegas de aulas e de teatro, e meus alunos, os daqui 
e os que encontrei nos caminhos teatrais de Deus. No interior desse labirinto nascem todos os dias meus deslumbramentos pelo teatro e minha fé como crítico.

\section{Bibliografia}

LEAL, Rine. En Primera Persona. Havana: Instituto cubano del libro, 1967.

MURRY, J. Middleton. El estilo literário. Cidade do México, 1951, in LEAL, Rine. ¿Qué es una antología? Prólogo a Teatro Cubano en un Acto. Ediciones R. La Habana, 1963, p10

STREHLER, Giorgio. Epístola moral a los críticos in Revista Espacio de Crítica e Investigación Teatral. Año 2. No. 3 Dezembro, 1987

POGOLOTTI Graziella, Palabras preliminares in Oficio de leer. Havana: ed. Letras Cubanas, 1983. 